\title{
An Enhanced Low Voltage Ride-Through Control Scheme of a DIFG based WTG Using Crowbar and Braking Chopper
}

\author{
Kishan Jayasawal, Khagendra Thapa \\ Department of Electrical Engineering, Pulchowk Campus, Institute of Engineering, Tribhuvan University, Nepal \\ Corresponding Authors: a jayasawalkishan@gmail.com, ${ }^{b}$ khagen@pcampus.edu.np
}

Received: 2020-08-21

Revised: 2021-01-23

Accepted: 2021-01-23

\begin{abstract}
:
The grid codes define low voltage ride-through (LVRT) as capability of wind turbine generator (WTG) to support the grid voltage by injecting reactive power and suppress the rise of DC-link voltage and inrush rotor current in the rotor side converter (RSC) of the doubly fed induction generator (DFIG) during a fault. Moreover, the rotor current increases significantly during severe disturbances if any protection schemes are not employed. Therefore, the protection schemes must be used to avoid the damage to the converter during a fault. This paper proposes an enhanced LVRT control scheme of a DFIG employing a crowbar in the RSC side and braking chopper across the DC-link capacitor. The DFIG is highly delicate to grid voltage fluctuation during a fault because the DFIG is directly linked to the grid via stator. During severe fault the crowbar regulates the rotor current within an acceptable range and the braking chopper discharges the DC-link capacitor via resistor within a safe limit. The proposed LVRT control scheme is performed for a 2.4-MW DFIG using a MATLAB/SIMULINK simulator. The results delineate that the proposed control scheme is able to rapidly decrease the rotor current and repress the escalation in DC-link voltage during a grid fault.
\end{abstract}

Keywords: Low voltage ride-through, Wind turbine generator, Doubly-fed induction generator, Crowbar, Braking chopper

\section{Introduction}

Power Generation from wind power plants (WPPs) has become very popular due to its advantages over conventional power plants since last few decades. The wind power generation has cumulatively reached 591 GW in 2018 [10] and is further increasing. So, the penetration of WPPs in the grid is increasing and there are the issues associated with integration of WPPs including stability issues. Many countries have set guidelines to counterpart issues and one of them is defined as requirements for low voltage ride-through (LVRT) capability [18]. Doubly fed induction generators (DFIGs) are popular wind power generator because they are highly efficient, provides variable speed operation, converter economy and ease to control active power and reactive power independently. However, DFIGs are highly delicate to grid voltage fluctuation during a fault because as being directly linked to the grid via stator whereas the rotor is linked via back-to-back converter for which overvoltage in the DC-link capacitor of the back-to-back converter is limited [19].

As the grid voltage dip occurs, the DFIG based wind power generator (WTG) is not able to transfer the generated power to the grid. Thus, this results in overcurrent in stator and rotor circuits of the DFIG and overvoltage in the DC-link capacitor [19]. Hence, to fulfil the LVRT requirements, the WTG is expected to suppress these overcurrents and overvoltage during a grid fault.

In $[1,5,8,11,12,14,15]$, a number of research works on the LVRT enhancement control strategy have been discussed. They mostly used crowbar protection strategy for the LVRT enhancement. In this, whenever grid fault occurs, the rotor side converter (RSC) is blocked and the overcurrent in it is limited by triggering the crowbar circuit which is installed in the rotor circuit [5, 12]. However, the RSC losses controllability of active and 
reactive power transmitted by the DFIG and also the energy gets accumulated in the DC-link capacitor thus increasing the voltage across it.

This paper discusses an enhanced LVRT control scheme which limits the rise in DC-link voltage by using braking chopper and suppresses the increase in the rotor current employing crowbar protection scheme. The proposed control scheme is tested for a 2.4-MW DFIG WTG using MATLAB/ SIMULINK simulator.

\section{Overview of DFIG}

The DFIG consists of back-to-back voltage source converter as shown in Figure 1. The DFIG is directly linked to the grid via stator, whereas the rotor is linked via slip rings and partially rated power electronic converters. The rating of power converters is generally $25 \%$ to $35 \%$ of the normal rating of the machine [2]. They can be controlled to regulate both active and reactive power being delivered to the grid independently of generator turning speed.

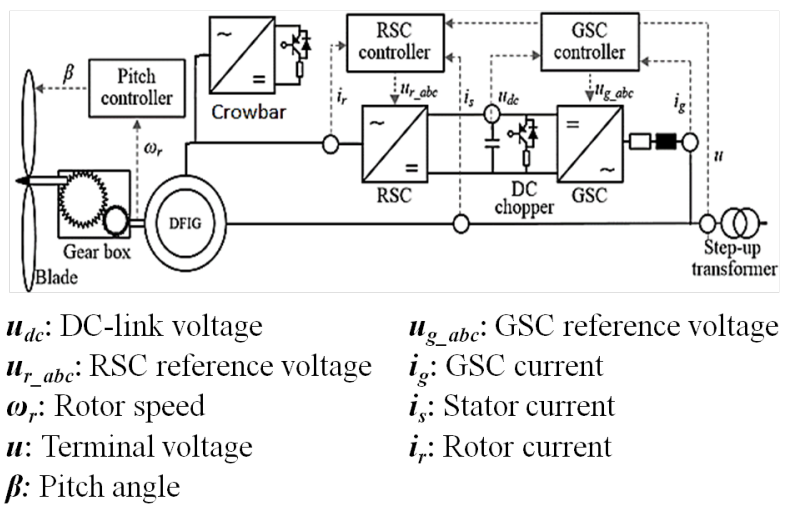

Figure 1: Typical configuration of a DFIG

The DFIG has ability to maximize and limit the power produced at low and high wind speeds respectively, which facilitates its use in high power application system [7].

The rotor allows bidirectional power flow to and from the grid. When the rotor spins at sub-synchronous speed, the machine acts as motor. Hence it starts to absorb power from the grid. However, when it operates at super-synchronous speed, it acts as generator and the power is transmitted to the grid from both stator and rotor of the DFIG.
The stator and rotor voltages can be written as [7]:

$$
\begin{aligned}
& V_{s}=R_{s} \cdot I_{s}+L_{s} \frac{d I_{s}}{d t}+L_{m} \frac{d I_{r}}{d t}+j \omega_{1} \cdot \varphi_{s} \\
& V_{r}=R_{r} \cdot I_{r}+L_{r} \frac{d I_{r}}{d t}+L_{m} \frac{d I_{s}}{d t}+j \omega_{\text {slip }} \cdot \varphi_{r}
\end{aligned}
$$

where $L_{s}, L_{r}$ and $L_{m}$ are the stator, rotor and magnetizing inductances respectively. $I_{s}$ and $I_{r}$ are stator and rotor currents, $\omega_{1}$ and $\omega_{\text {slip }}$ are the stator and slip angular speed respectively, and, $\varphi_{s}$ and $\varphi_{r}$ are the stator and rotor fluxes respectively.

In synchronous reference frame fixed to the stator flux, the active and reactive power in relationship with the rotor current components, can be written as:

$$
\begin{aligned}
& P_{s}=\frac{3}{2} \omega_{s} \frac{L_{m}^{2}}{L_{s}} I_{m o} \cdot I_{r q} \\
& Q_{s}=\frac{3}{2} \omega_{s} \frac{L_{m}^{2}}{L_{s}}\left(I_{r d}-I_{m o}\right) \cdot I_{m o}
\end{aligned}
$$

Where $P_{s}$ and $Q_{s}$ are active and reactive power of stator respectively. $I_{d r}$ and $I_{r q}$ are direct and quadrature component of rotor current, respectively. From equation (3) and (4), it can be inferred that $I_{r q}$ is responsible to control the stator active power while $I_{r d}$ is responsible to control the stator reactive power. The $R_{r q}$ reference can be obtained from optimal power tracking curve provides whereas $I_{r d}$ reference can be obtained from AC voltage controller. The equivalent stator magnetizing current $I_{m o}$ is defined as:

$$
\varphi_{s}=L_{s} \cdot I_{s}+L_{r} \cdot I_{r}=L_{s} \cdot I_{m o}
$$

\subsection{Rotor Side Converter (RSC) Controller}

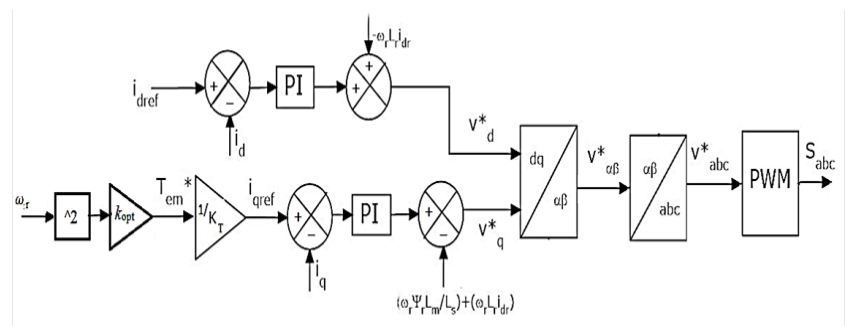

Figure 2: Rotor side Converter Controller 
The vector control strategy is imposed to RSC to regulate stator active power and reactive power. The quadrature component of rotor current is proportional to torque which is used to regulate the active power whereas direct component of rotor current is used to control the reactive power.

The electromagnetic torque is written as [1]:

$$
\begin{aligned}
& T_{e m}=\frac{3}{2} p \times \frac{L_{m}}{L_{s}}\left(\Psi_{q s} i_{d r}-\Psi_{d s} i_{d r}\right) \\
& T_{e m}=\frac{3}{2} p \times \frac{L_{m}}{L_{s}}\left|\Psi_{s}\right| i_{d r}
\end{aligned}
$$

The reference $I_{q r}$ is written as:

$$
I_{q r} *=\frac{T_{e m}^{*}}{k_{T}} \quad \text { i.e. } \quad T_{e m} \propto I_{q r}
$$

Similarly,

$$
\begin{gathered}
Q_{s}=\frac{3}{2}\left(v_{q s} i_{d s}-v_{d s} i_{q r}\right) \\
Q_{s}=K_{Q}\left(i_{d r}-\frac{\left|\Psi_{S}\right|}{L_{m}}\right) \quad \text { i.e., } \quad Q_{s} \propto I_{d}
\end{gathered}
$$

\subsection{Rotor Current Dynamics during Voltage dip}

The grid fault can cause overcurrents in the rotor circuit and a high DC-link voltage. This is mainly due to the small rating of the converters, which is unable to produce the required voltage to control the generator [7].

Neglecting the stator and rotor resistance, multiplying equation (2) by and subtracting from equation (1) after simplification we get:

$$
\begin{aligned}
V_{s} & =L_{m}\left(1-\frac{L_{s} L_{r}}{L_{m}{ }^{2}}\right) \frac{d I_{r}}{d t} \\
& +j\left(\omega_{1} \cdot \varphi_{s}-\frac{L_{s}}{L_{m}} \omega_{\text {slip }} \cdot \varphi_{\gamma}\right)+\frac{L_{s}}{L_{m}} V_{r}
\end{aligned}
$$

During steady state condition $=0$, therefore equation $(8)$ can be written as:

$$
V_{s}-j\left(\omega_{1} \cdot \varphi_{s}-\frac{L_{s}}{L_{m}} \omega_{s l i p} \cdot \varphi_{r}\right)=\frac{L_{s}}{L_{m}} V_{r}
$$

When a grid fault occurs, there will instant drop in AC voltage, $\Delta V_{s}$. But, at that same instant, the stator and rotor flux remain fixed as $\varphi_{s}=\int V_{s} d t$, and $\varphi_{r}=\int V_{r} d t$. In reference to equation (8) the $j\left(\omega_{1} \cdot \varphi_{s}-\frac{L_{s}}{L_{m}} \omega_{s l i p} \cdot \varphi_{r}\right)$ term will not change. Hence, from equation 8 , the variation in the stator voltage at the instant of fault can be expressed as:

$$
\Delta V_{s}=L_{m}\left(1-\frac{L_{s} L_{r}}{L_{m}^{2}}\right) \frac{d I_{r}}{d t}+\frac{L_{s}}{L_{m}} \Delta V_{r}
$$

Therefore, to nullify the change in rotor current i.e. $d I_{r} / d t=0$, during fault, large step change in rotor voltage must be done. Thus equation (10) can be further expressed as:

$$
V_{s}=\frac{L_{s}}{L_{m}} \Delta V_{r}
$$

If we are able to satisfy equation (10), the change in the rotor current will be negligible and the crowbar protection would no longer be required. But for a large change in stator voltage i.e. $\Delta V_{s}$, the RSC is unable to produce required $\Delta V_{r}$ due to its limited voltage capability of only about 20-30\%. Typically, During the grid fault, the tolerable limit of rotor current is 2 p.u. and that of DC-link voltage is 1.2 times the nominal value [4].

\subsection{Overview of Crowbar Protection}

A crowbar protection scheme is conventionally a resistive network used to limit the over-currents in the rotor circuit connected parallelly as shown in Figure 1. During over-currents, the crowbar circuit is triggered to disable the RSC (by cutting off the pulses of the converter) so that the generator is prevented from turning into a squirrel cage induction generator.

The value resistance of crowbar resistor is to be considered very carefully. It should be high to an extend such that it can limit the short circuit rotor current and low to an extend such that it can avoid too high voltage ripple in the rotor circuit [12].

\subsection{Overview of Braking Chopper Protection}

A braking chopper is a protection scheme that shorts the DC-link capacitor, whenever DC-link voltage 
exceeds fixed threshold, through a power resistor. The resister and a switch connected in series are connected in parallel with the DC-link capacitor to dissipate power generated, during the voltage dip, as required as shown in Figure 3.

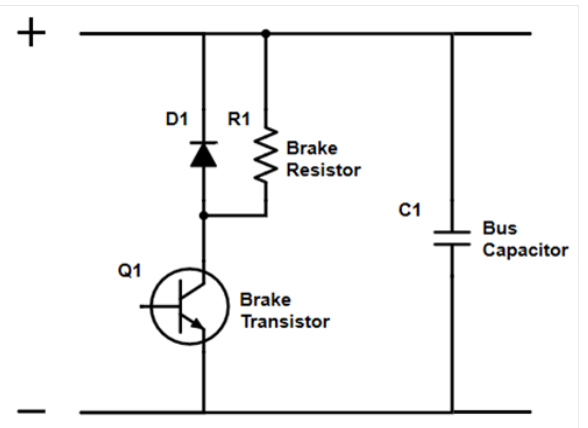

Figure 3: Schematic diagram of Braking Chopper

During grid faults, transient over-currents are observed in rotor. To reduce adverse effects, the RSC controller may be disabled and the power transmitted through the rotor can be dissipated via the crowbar. However, this results in rapid rise in the DC-link voltage. To avoid this, braking chopper is triggered so that the power in the DC link capacitor is sunk through the brake resistor and thus preventing dangerous overvoltage in the DC-link capacitor [13].

\subsection{Grid Codes for LVRT requirements}

Table 1 shows the specifications for fault ride-through in various grid codes across the globe. Figure 4 represents the grid code for the LVRT requirements of National grid code in England and Wales, Red Electrica in Spain (ESP), Eirgrid in Ireland, and E. On Netz in German, respectively $[3,6,9,16]$. During the voltage dip occurrence, WTG has to inject the reactive current to the grid to support the grid voltage as shown in Figure 5. The amount of injected reactive power depends on the system rated current, reactive current delivered to the grid before the dip occurrence and the percentage of change in the grid voltage during the voltage dip. When the voltage variation is greater than 10 percent, the WTG has to back up the grid with the injection of the specified reactive current to secure the grid stability. The area from 0.9 times to 1.1 times grid voltage of the system is termed the dead band. In this area, the reactive current injected into the grid is not required. After the fault occurs, the reactive current is supplied and a 100 percent reactive current injected is possible if necessary [17].
Table 1: Characteristics of fault ride-through specifications in various grid codes

\begin{tabular}{|l|c|c|c|c|}
\hline Grid Code & $\begin{array}{c}\text { Fault } \\
\text { duration } \\
(\mathrm{ms})\end{array}$ & $\begin{array}{c}\text { Fault } \\
\text { duration } \\
\text { (cycles) }\end{array}$ & $\begin{array}{c}\text { Min. } \\
\text { voltage } \\
\text { level } \\
\text { (p.u.) }\end{array}$ & $\begin{array}{c}\text { Voltage } \\
\text { restoration } \\
\text { (s) }\end{array}$ \\
\hline Germany (Eon) & 150 & 7.5 & 0 & 1.5 \\
\hline UK & 140 & 7 & 0 & 1.2 \\
\hline Ireland & 625 & 31.25 & 0.15 & 3 \\
\hline Nordel & 250 & 12.5 & 0 & 0.75 \\
\hline $\begin{array}{l}\text { Denmark } \\
\text { (<100 kV) }\end{array}$ & 140 & 7 & 0.25 & 0.75 \\
\hline $\begin{array}{l}\text { Denmark } \\
\text { (>100kV) }\end{array}$ & 100 & 5 & 0 & 10 \\
\hline $\begin{array}{l}\text { Belgium } \\
\text { (large voltage dips) }\end{array}$ & 200 & 10 & 0 & 0.7 \\
\hline $\begin{array}{l}\text { Belgium } \\
\text { (small voltage dips) }\end{array}$ & 1500 & 75 & 0.7 & 1.5 \\
\hline Canada (AESO) & 625 & 37.5 & 0.15 & 3 \\
\hline $\begin{array}{l}\text { Canada } \\
\text { (Hydro-Quebec) }\end{array}$ & 150 & 9 & 0 & 1 \\
\hline USA & 625 & 37.5 & 0.15 & 3 \\
\hline Spain & 500 & 25 & 0.2 & 1 \\
\hline Italy & 500 & 25 & 0.2 & 0.8 \\
\hline $\begin{array}{l}\text { Sweden } \\
\text { (<100 MW) }\end{array}$ & 250 & 12.5 & 0.25 & 0.25 \\
\hline $\begin{array}{l}\text { Sweden } \\
(>100 \text { MW) }\end{array}$ & 250 & 12.5 & 0 & 0.8 \\
\hline New Zealand & 200 & 10 & 0 & 1 \\
\hline
\end{tabular}

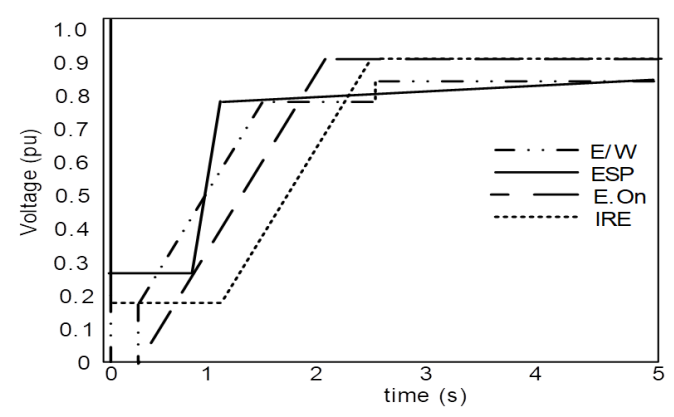

Figure 4: Grid code for LVRT specifications

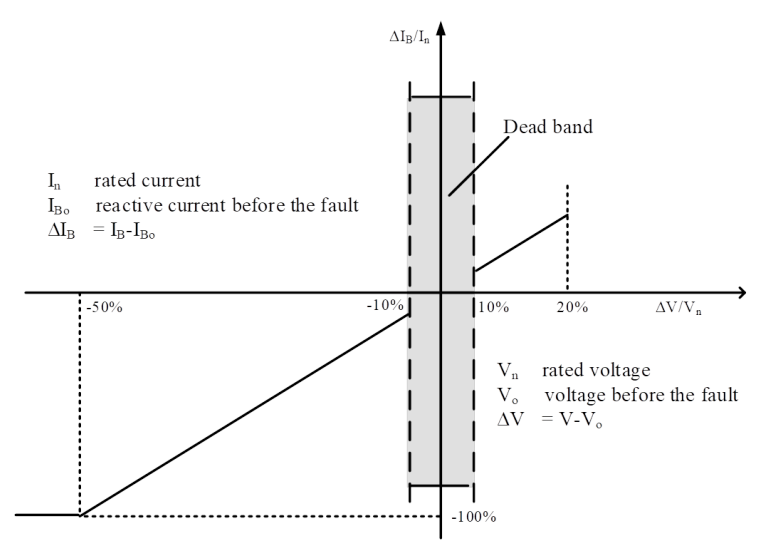

Figure 5: Reactive current delivered to the grid 


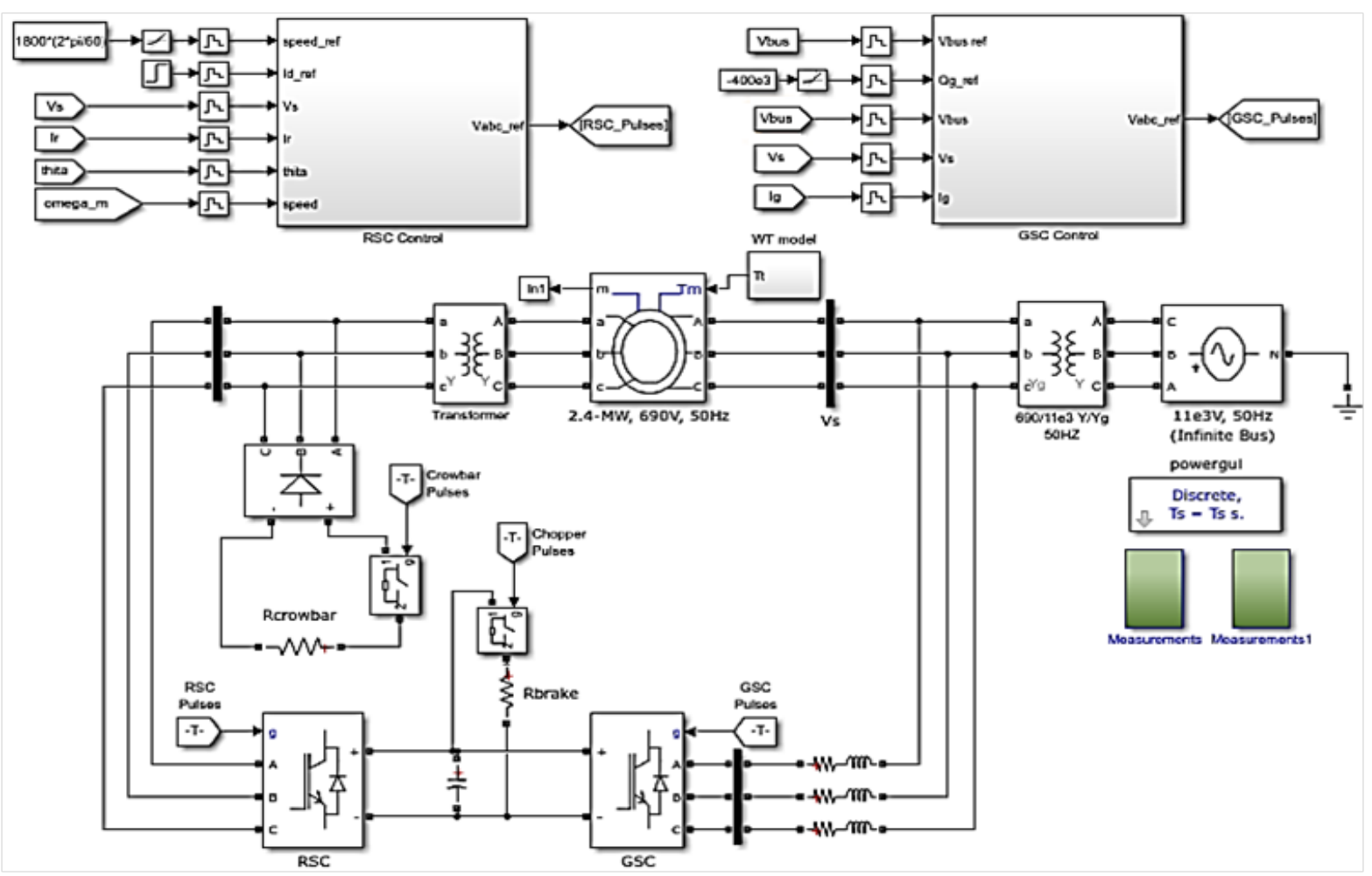

Figure 6: MATLAB/SIMULINK model system

\section{Model System}

Figure 6 represents the MATLAB/Simulink model DFIG with proposed control scheme. The 2.4-MW DFIG WTG consisting of three blades with radius of 42 $\mathrm{m}$ is operated with wind speed of $11 \mathrm{~m} / \mathrm{s}$. The power curve of 2.4 MW DFIG is shown in Figure 7, where 12 $\mathrm{m} / \mathrm{s}$ is rated speed and $4 \mathrm{~m} / \mathrm{s}$ and $25 \mathrm{~m} / \mathrm{s}$ are the cut-in and cut-off speed respectively. A symmetrical voltage dip of 0.9-p.u. for $200 \mathrm{~ms}$ is simulated at $\mathrm{t}=6 \mathrm{~s}$ as shown in Figure 8 following the German grid code (E. On). When the voltage dip occurs, the DC-link voltage and the rotor current rises rapidly as shown in Figure 9 and Figure 10 respectively when no protection is used.

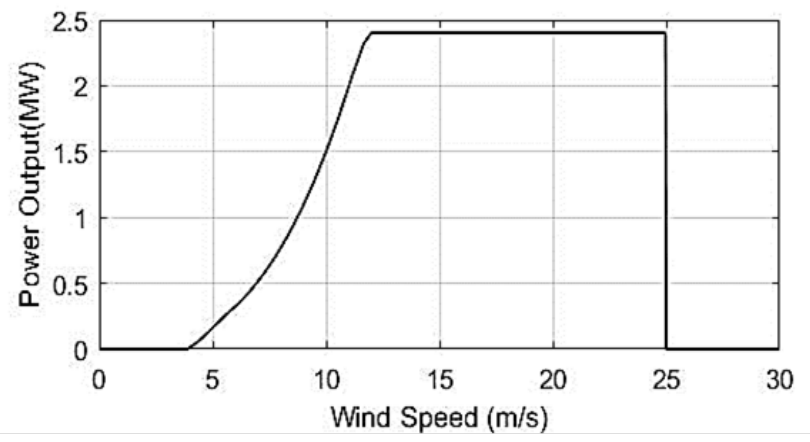

Figure 7: Power curve for a 2.4-MW DFIG

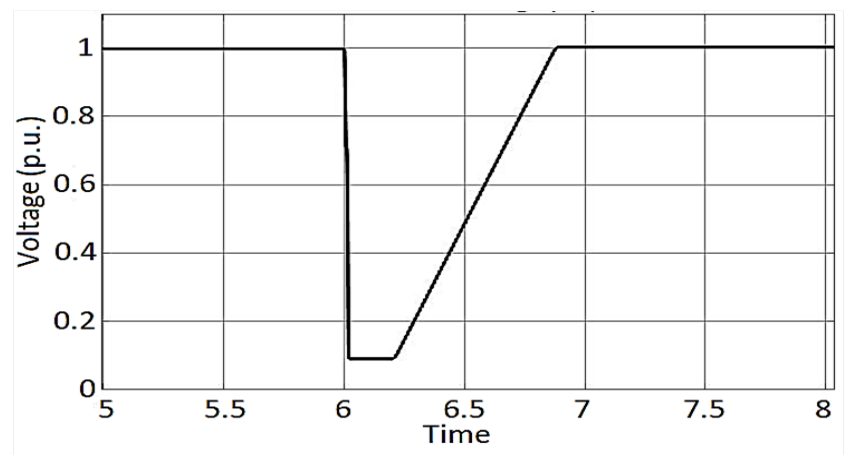

Figure 8: Grid voltage dip lasting 200ms

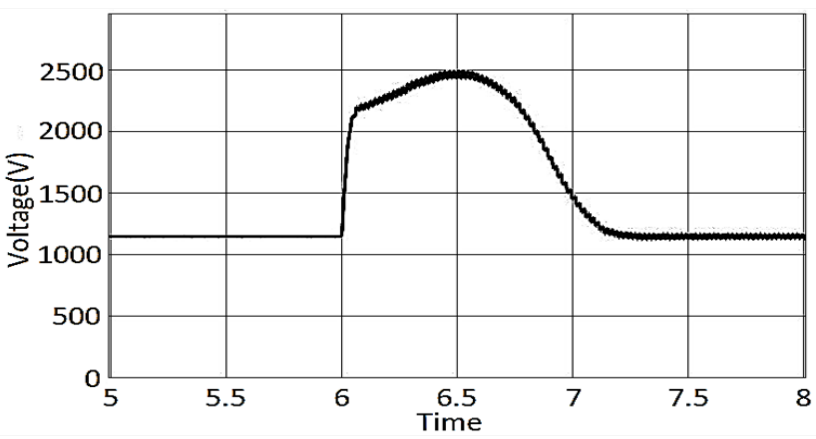

Figure 9: DC-link voltage of DFIG without protection system 


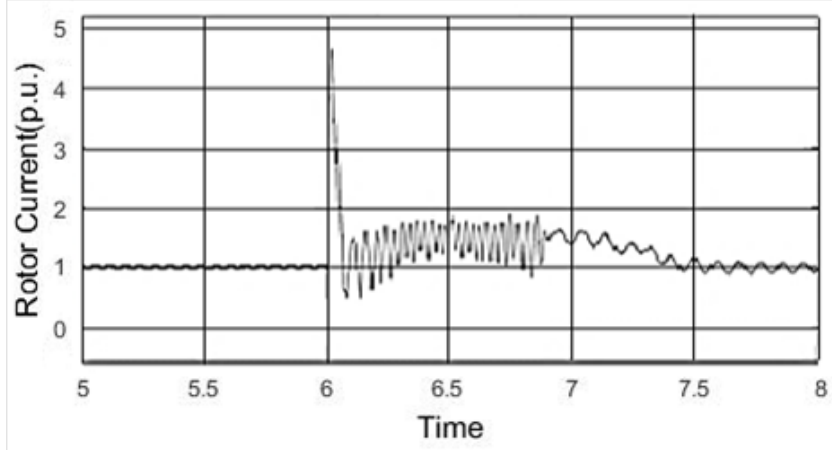

Figure 10: Rotor current for case without protection system

\section{Results and Discussion}

Figure 11 and 12 show the results of the proposed system. At $\mathrm{t}=6 \mathrm{~s}$, a voltage dip occurs and ends at $\mathrm{t}=6.2$ $\mathrm{s}$. When the dip occurs, the rotor current increases and whenever it is beyond reference current, the RSC is switched off and the crowbar is triggered thus providing a bypass path for the current, hence limiting the overcurrent in the RSC as shown in Figure 11.

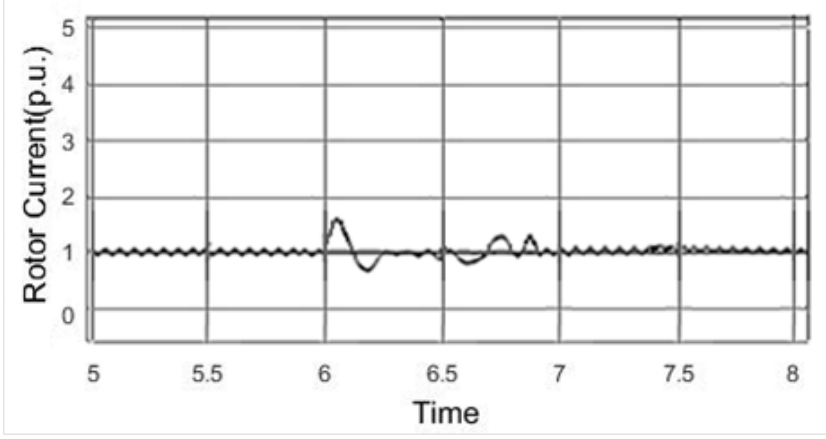

Figure 11: Rotor current for the case with both crowbar and braking chopper protection system

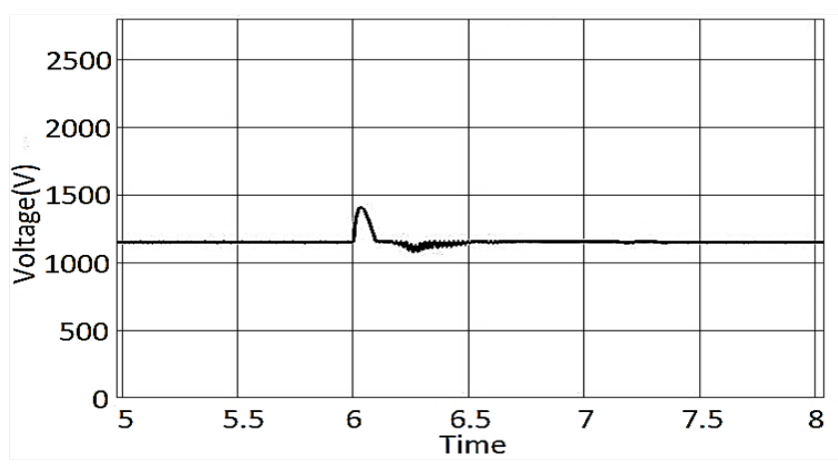

Figure 12: DC-link voltage for case with both crowbar and braking chopper protection system

Comparing Figure 11 with Figure 10, it can be inferred that there is a decrease in the rotor current, initially the peak current was approximately 5 p.u. but after protection the current is limited to approximately 1.5 p.u.

Similarly, the active power reduces at the terminals of the DFIG due to reduction in the terminal voltage of DFIG because of the fault. Voltage in the DC-link rises beyond preset threshold voltage as shown in Figure 9, the braking chopper is triggered and overvoltage in the capacitance is sunk, thus limiting the DC-link voltage as shown in Figure 12. Comparing Figure 12 with Figure 9, it is observed that the maximum DC-link voltage has decreased from 2500 volts to 1400 volts which is within the acceptable limit.

The results clearly show that the proposed LVRT control scheme is successfully able to control the rotor current and DC-link voltage during the symmetric grid fault by triggering the crowbar and braking chopper protection circuits thus enhancing the LVRT capability of the DFIG based WTG system.

\section{Conclusion}

In this paper, an enhanced LVRT control scheme for DFIG based WTG is proposed that uses both crowbar and braking chopper to control the overvoltage and overcurrent in the DC-link capacitor and rotor current of the RSC of a DFIG respectively. The crowbar protection system employed in the RSC of a DFIG suppresses the rotor overcurrent by providing a bypass path for the current whereas the braking chopper connected across the DC-link capacitor suppresses the overvoltage in the DC-link capacitor. Consequently, both RSC and the DC-link capacitor are protected. Hence, the LVRT capability of the DFIG based WTG is enhanced.

\section{References}

[1] G. Abad, J. Lopez, M. Rodriguez, L. Marroyo, and G. Iwanski, Doubly fed induction machine: modeling and control for wind energy generation. John Wiley \& Sons, 2011, vol. 85.

[2] C. Amendola and D. Gonzaga, "Fuzzy-logic control system of a variable-speed variable-pitch wind-turbine and a double-fed induction generator," in Seventh International Conference on Intelligent Systems Design and Applications (ISDA 2007). IEEE, 2007, pp. 252-257. 
[3] EirGrid Grid Code, 2011.

[4] S. O. Z. Elabideen, A. A. Helal, and I. F. El-Arabawy, "Low Voltage Ride through Capability Techniques for DFIG-based Wind Turbines," International Journal of Energy and Power Engineering, vol. 10, no. 7, pp. 910918, 2016.

[5] M. Ezzat, M. Benbouzid, S. Muyeen, and L. Harnefors, "Low-voltage ride-through techniques for DFIG-based wind turbines: state-of-the-art review and future trends," in IECON 2013-39th Annual Conference of the IEEE Industrial Electronics Society. IEEE, 2013, pp. 76817686.

[6] J. Fernandez, "Grid codes for wind energy in Spain and developments in Europe," Large Scale Integration of Wind Energy, Brussels, Belgium, 2006.

[7] S. Foster, L. Xu, and B. Fox, "Coordinated control and operation of DFIG and FSIG based Wind Farms," in 2007 IEEE Lausanne Power Tech. IEEE, 2007, pp. 522-527.

[8] E. Gatavi, A. Hellany, M. Nagrial, and J. Rizk, "Low voltage ride-through enhancement in DFIG-based wind turbine," in 2016 IEEE Electrical Power and Energy Conference (EPEC). IEEE, 2016, pp. 1-6.

[9] E. On, "Grid code high and extra high voltage," ON Nets GmbH, Bayreuth, Germany, 2006.

[10] G. W. E. Council, "Global status of wind power," Online at http://gwec. net/global-figures/windenergy-global-status, 2018.

[11] J. Lopez, P. Sanchis, X. Roboam, and L. Marroyo, "Dynamic behavior of the doubly fed induction generator during three-phase voltage dips," IEEE Transactions on Energy conversion, vol. 22, no. 3, pp. 709-717, 2007.
[12] O. Noureldeen, "Behavior of DFIG wind turbines with crowbar protection under short circuit," International Journal of Electrical \& Computer Sciences IJECS-IJENS, vol. 12, no. 3, pp. 32-37, 2012.

[13] G. Pannell, B. Zahawi, D. J. Atkinson, and P. Missailidis, "Evaluation of the performance of a DC-link brake chopper as a DFIG low-voltage fault-ride-through device," IEEE Transactions on energy conversion, vol. 28, no. 3, pp. 535-542, 2013.

[14] K. B. Thapa and K. Jayasawal, "Pitch Control Scheme for Rapid Active Power Control of a PMSG-Based Wind Power Plant," in 2020 IEEE International Conference on Power Electronics, Smart Grid and Renewable Energy (PESGRE2020). IEEE, 2020, pp. 1-6.

[15] K. Thapa, K. Jayasawal, and G. Marasini, "Rapid LVRT Control of a DFIG-Based Wind Power Plants Based on Adaptive I Q-V Characteristics," in 2018 IEEE International Conference on Power Electronics, Drives and Energy Systems (PEDES). IEEE, 2018, pp. 1-5.

[16] The Grid Code, Issue 4 Revision 2. Great Britain: National Grid Electricity Transmission Std.

[17] The Grid Code, Issue 4 Revision 2. Great Britain: National Grid Electricity Transmission plc., 2012.

[18] M. Tsili and S. Papathanassiou, "A review of grid code technical requirements for wind farms," IET Renewable power generation, vol. 3, no. 3, pp. 308-332, 2009.

[19] C. Wessels and F. W. Fuchs, "Fault ride through of DFIG wind turbines during symmetrical voltage dip with crowbar or stator current feedback solution," in 2010 IEEE Energy Conversion Congress and Exposition. IEEE, 2010, pp. 2771-2777. 
